Provided for non-commercial research and education use. Not for reproduction, distribution or commercial use.

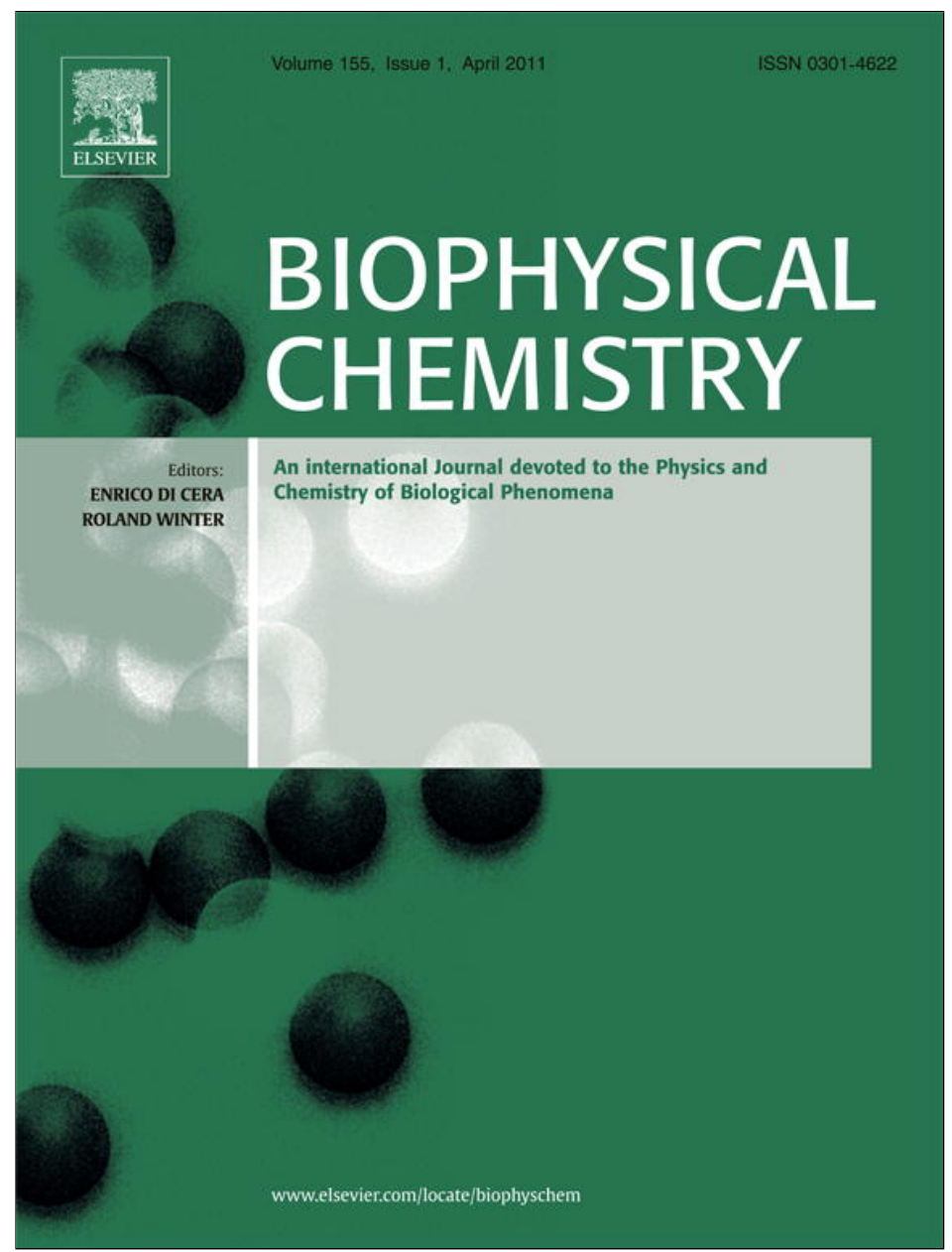

This article appeared in a journal published by Elsevier. The attached copy is furnished to the author for internal non-commercial research and education use, including for instruction at the authors institution and sharing with colleagues.

Other uses, including reproduction and distribution, or selling or licensing copies, or posting to personal, institutional or third party websites are prohibited.

In most cases authors are permitted to post their version of the article (e.g. in Word or Tex form) to their personal website or institutional repository. Authors requiring further information regarding Elsevier's archiving and manuscript policies are encouraged to visit:

http://www.elsevier.com/copyright 


\title{
Catalytic mechanism in successive two-step protein-film voltammetry-Theoretical study in square-wave voltammetry
}

\author{
Rubin Gulaboski*, Ljupčo Mihajlov \\ Faculty of Agriculture, Goce Delčev University, Štip, Macedonia
}

\section{A R T I C L E I N F O}

\section{Article history:}

Received 10 January 2011

Received in revised form 27 January 2011

Accepted 30 January 2011

Available online 23 February 2011

\section{Keywords:}

Protein-film voltammetry

Feedback mechanism

Surface redox reactions

Mathematical modeling

Square-wave voltammograms

Michaelis-Menten constant

\begin{abstract}
A B S T R A C T
Protein-film voltammetry is established as an effective tool that provides insight to the redox features of various lipophilic proteins by using a simple methodology. Although the protein-film experimental set up is relatively simple, the redox mechanisms of many proteins are quite complicated, and very often they cannot be resolved without having support from adequate mathematical models. In this work we continue our contribution to modeling relevant redox mechanisms in protein-film voltammetry. We present results from the theoretical simulations of catalytic mechanism at the two-step successive surface redox reaction under conditions of square-wave voltammetry. This mechanism is assigned as a surface $\mathrm{EEC}^{\prime}$, and it can be presented by the following simplified scheme: $\mathrm{A}($ ads $)+$ ne $-\rightleftarrows \mathrm{B}($ ads $)+$ ne $-\rightleftarrows \mathrm{C}($ ads $)+$ Substrate $\stackrel{k_{\text {cat }}}{\longrightarrow} \mathrm{B}($ ads $)$. Our attention is focused on several phenomena of this complex protein-film mechanism, while we give set of qualitative criteria to distinguish this mechanism from similar ones studied under voltammetric conditions. Moreover, we also provide hints to use methodologies for the determination of thermodynamic and kinetic parameters relevant to the protein-film $\mathrm{EEC}^{\prime}$ mechanism. The considered protein-film $\mathrm{EEC}^{\prime}$ mechanism is applicable to all lipophilic redox proteins that undergo electrochemical transformations in more than one successive electron steps. Such examples exist by proteins containing quinone moiety and some polyvalent ions of transition metals as redox active sites.
\end{abstract}

(c) 2011 Elsevier B.V. All rights reserved.

\section{Introduction}

Since the establishment of the basic principles of protein film voltammetry (PFV) more than a decade ago [1], this technique became a valuable tool for studying redox enzymes of different natures by using a rather simple approach [1-12]. The PFV methodology provides access to a number of information related to the physiological activities of redox-active proteins from experiments commonly performed in the standard three-electrode voltammetric set-up $[1-3,7,11,12]$. The basic principles of this technique consider adsorption of a given protein on an electrode surface, mainly by selfassembling from aqueous electrolytes [1-3]. By making a solid electrode modified with adsorbed enzyme, we make a sort of surrogate partner that mimics the physiological redox processes of a chosen protein. When controlled bias is applied to such proteinmodified electrode, then we can monitor the redox features of the adsorbed protein by using suitable voltammetric technique. Hitherto, by applying a cyclic voltammetry, lots of valuable experimental data have been obtained related to the protein redox chemistry [1-12]. The obtained results from the PFV experiments are commonly analyzed in terms of plots of peak potentials, peak currents or half-peak widths

\footnotetext{
* Corresponding author.

E-mail address: rubin.gulaboski@ugd.edu.mk (R. Gulaboski).
}

against the applied scan rates [1-4,7,12]. In this way we get important thermodynamic and kinetic information related to the physiological activities coupled to protein redox activity $[1-3,7,9,12]$. Protein film voltammetry can be used to study the electron transfer processes between the electrode and the redox site of given proteins, but it can be also explored to provide insight into the coupled chemical reactions between the considered protein and a given substrate $[3,7,10,12]$. The chemical reaction between an electrochemically reduced/oxidized protein and a defined substrate, which leads to regeneration of the initial electroactive reactant, is commonly described as a catalytic EC' mechanism [13,14]. In this electrochemical mechanism, the initial redox form of the protein regenerates during the time-scale of the voltammetric experiment, and that phenomenon is portrayed in a very typical catalytic current-potential profile [13-17]. Usually, the chemical step by such systems is considered to be an irreversible reaction of first-order. Hitherto, several theoretical works have been already dedicated to the catalytic mechanism in protein-film methodology in various voltammetric techniques, and different aspects of the theoretical features of this reaction can be found elsewhere [13-25]. The mentioned theoretical models in Refs. [13-25] are suitable to proteins containing a redox center that undergoes a single-step electrochemical transformation. However, there are many classes of proteins containing redox centers that can undergo redox transformations in several successive electron steps $[7,8,26]$. Of these, the most present are proteins with quinone moiety, 
or polyvalent ions of transition metals like Mo, Mn, W, or Co as redox centers [26]. The redox transformations of the aforementioned proteins can only be described by theoretical models considering successive two-step electron transfer. In the last few years, we started theoretical considerations of various redox mechanisms relevant to protein-film voltammetry, and we published scores of theoretical and experimental works in the past decade $[17,21,22,25,27-34]$. In this paper we consider the surface catalytic mechanism that follows the two-step surface EE (electron-electron) redox reaction, which can be described by the following reaction scheme:

$$
\begin{aligned}
& \text { Electrochemical step \#1 : A(ads) }+ \text { ne }-\rightleftarrows \mathrm{B}(\text { ads }) \\
& \text { Electrochemical step \#2 : } \mathrm{B}(\text { ads })+\text { ne }-\rightleftarrows \mathrm{C}(\text { ads }) \\
& \text { Catalytic step : } \quad \mathrm{C}(\text { ads })+\text { Substrate } \stackrel{k_{\text {cat }}}{\longrightarrow} \mathrm{B}(\text { ads }) .
\end{aligned}
$$

The common designation of this complex protein-film redox mechanism in the electrochemical terminology is a surface EEC', or surface EECat $[13,14]$. We describe in this paper for the first time the theoretical features of this complex redox mechanism under conditions of square-wave voltammetry. We use the square-wave voltammetry (SWV) as a working technique since it is one of the most popular and most exploited in the family of the pulse voltammetric techniques $[13,14,17,21-25]$. In the present time, the SWV is considered as "electrochemical spectroscopy" due to its ability to provide closer insight into various redox mechanisms $[13,17,21]$. The considered theoretical model is relevant to all lipophilic redox proteins that can undergo redox transformations in more than one successive electron steps, as those containing quinone moiety or polyvalent ions of some transition metals as redox active sites [26].

\section{Mathematical model}

The considered catalytic two-step protein-film mechanism (in the further text designated as protein-film $\mathrm{EEC}^{\prime}$ ) is described by the following reaction scheme:

Electrochemical step \#1:A(ads) + ne $-\rightleftarrows \mathrm{B}($ ads $)$

Electrochemical step \#2: $\mathrm{B}(\mathrm{ads})+$ ne $-\rightleftarrows \mathrm{C}(\mathrm{ads})$

Catalytic step : $\quad \mathrm{C}(\mathrm{ads})+\mathrm{Sub} \stackrel{k_{\text {cat }}}{\longrightarrow} \mathrm{B}(\mathrm{ads})$.

At the beginning of the experiment, there is only compound A present in the system, and it is firmly adsorbed at the electrode surface. The compound $C$ is generated electrochemically via redox transformation of $B$. The compound $\mathrm{B}$ is generated via electrochemical transformation of compound $\mathrm{A}$, but also via catalytic regeneration reaction of the electrochemically generated product $\mathrm{C}$ with the substrate Sub. The term "catalytic" stands to show that the chemical reaction regenerates B from C. The prime (') on the $\mathrm{C}$ in the abbreviation $\mathrm{EEC}^{\prime}$ represents a catalytic process. We consider that all redox active participants in the electrode mechanism (I) (A, B, and C) are strongly adsorbed on the electrode surface following a Langmuir isotherm, and there are no interactions between the adsorbed species. In addition, we assume that the adsorption constants of all adsorbed species are identical. By Sub we assign the electrochemically inactive substrate (or catalytic reagent), whose bulk concentration in solution is much higher than the initial concentration of all adsorbed electroactive species. Therefore, the chemical step in the reaction mechanism (I) is considered to be of pseudo-first order. $k_{\text {cat }}\left(\mathrm{s}^{-1}\right)$ is a pseudo first order catalytic rate constant defined as $k_{\text {cat }}=k_{\text {cat }}{ }^{\prime} c(S u b)$, where $k_{\text {cat }}{ }^{\prime}$ is the real chemical (catalytic) rate constant or MichaelisMenten constant $\left(\mathrm{mol}^{-1} \mathrm{~cm}^{3} \mathrm{~s}^{-1}\right)$, while $c(\mathrm{Sub})$ is the molar concentration of the substrate Sub. During the voltammetric experiment, the mass transport of all species is neglected. The electrode mechanism (I) is mathematically represented by the following set of equations:

$\mathrm{d} \Gamma(\mathrm{A}) / \mathrm{d} t=-I_{1} /(n F S)$ $\mathrm{d} \Gamma(\mathrm{B}) / \mathrm{d} t=I_{1} /(n F S)-I_{2} /(n F S)+k_{\mathrm{cat}} \Gamma(\mathrm{C})$

$\mathrm{d} \Gamma(\mathrm{C}) / \mathrm{d} t=I_{2} /(n F S)-k_{\mathrm{cat}} \Gamma(\mathrm{C})$

with the following initial and boundary conditions

$$
\begin{aligned}
& t=0 ; \Gamma(\mathrm{A})=\Gamma^{*} ; \Gamma(\mathrm{B})=\Gamma(\mathrm{C})=0 \\
& t>0 ; \Gamma(\mathrm{A})+\Gamma(\mathrm{B})+\Gamma(\mathrm{C})=\Gamma^{*} .
\end{aligned}
$$

With $\Gamma(\mathrm{A}), \Gamma(\mathrm{B})$, and $\Gamma(\mathrm{C})$ we assign the surface concentrations of the species $A, B$, and $C$, respectively, while $\Gamma^{*}$ is the total surface concentration of all species. $\Gamma$ is a symbol of the surface concentration of particular specie that is a function of time $t$. By $I$ we assign the current, $S$ is the electrode surface area, $F$ is the Faraday's constant, while $n$ is a number of exchanged electrons in an elementary act of electrochemical transformation. The analytical solutions of Eqs. (1)-(3) were obtained with the help of Laplace transformations. The solutions for the surface concentrations of the electroactive species A, B, and C in their integral forms read:

$$
\begin{aligned}
& \Gamma(\mathrm{A})=\Gamma(\mathrm{A})^{*}-\int_{0}^{t} \frac{I_{1}(\tau)}{n F S} \mathrm{~d} \tau \\
& \Gamma(\mathrm{B})=\int_{0}^{t} \frac{I_{1}(\tau)}{n F S} \mathrm{~d} \tau-\int_{0}^{t} \frac{I_{2}(\tau)}{n F S} \exp \left[-k_{\text {cat }}(t-\tau)\right] \mathrm{d} \tau \\
& \Gamma(\mathrm{C})=\int_{0}^{t} \frac{I_{2}(\tau)}{n F S} \exp \left[-k_{\text {cat }}(t-\tau)\right] \mathrm{d} \tau .
\end{aligned}
$$

If the Buttler-Volmer formalism applies at the electrode surface, then the following conditions hold:

$$
\begin{gathered}
\frac{I_{1}}{n F S}=k_{s, 1} \exp \left(-\alpha \phi_{1}\right)\left[\Gamma(\mathrm{A})-\exp \left(\phi_{1}\right) \Gamma(\mathrm{B})\right] \\
\frac{I_{2}}{n F S}=k_{\mathrm{s}, 2} \exp \left(-\alpha \phi_{2}\right)\left[\Gamma(\mathrm{B})-\exp \left(\phi_{2}\right) \Gamma(\mathrm{C})\right] .
\end{gathered}
$$

In Eqs. (9) and (10), with $k_{\mathrm{s}, 1}\left(\mathrm{~s}^{-1}\right)$ and $k_{\mathrm{s}, 2}\left(\mathrm{~s}^{-1}\right)$ we assign the heterogeneous electron exchange rate constant corresponding to the standard redox potential of first $E_{\mathrm{A} / \mathrm{B}}^{\ominus}$ and second $E_{\mathrm{B} / \mathrm{C}}^{\ominus}$ electron transfer steps of the electrode reaction (I), respectively, $\alpha$ is the cathodic electron transfer coefficient, while $\phi_{1}=\frac{n F}{R T}\left(E-E_{\mathrm{A} / \mathrm{B}}^{\ominus}\right)$ and $\phi_{2}=\frac{n F}{R T}\left(E-E_{\mathrm{B} / \mathrm{C}}^{\ominus}\right)$ are the dimensionless relative electrode potentials. By substituting Eqs. (6) and (7) into Eq. (9), and Eqs. (7) and (8) into Eq. (10) one gets:

$$
\begin{aligned}
\frac{I_{1}}{n F S}= & k_{\mathrm{s}, 1} \exp \left(-\alpha \phi_{1}\right)\left[\Gamma^{*}-\int_{0}^{t} \frac{I_{1}(\tau)}{n F S} \mathrm{~d} \tau-\exp \left(\phi_{1}\right)\right. \\
& \left.\times\left(\int_{0}^{t} \frac{I_{1}(\tau)}{n F S} \mathrm{~d} \tau-\int_{0}^{t} \frac{I_{2}(\tau)}{n F S} \exp \left[-k_{\mathrm{cat}}(t-\tau)\right] \mathrm{d} \tau\right)\right] \\
\frac{I_{2}}{n F S}= & k_{\mathrm{s}, 2} \exp \left(-\alpha \phi_{2}\right)\left[\int_{0}^{t} \frac{I_{1}(\tau)}{n F S} \mathrm{~d} \tau-\int_{0}^{t} \frac{I_{2}(\tau)}{n F S} \exp \left[-k_{\mathrm{cat}}(t-\tau)\right] \mathrm{d} \tau-\exp \left(\phi_{2}\right)\right. \\
& \left.\times\left(\int_{0}^{t} \frac{I_{2}(\tau)}{n F S} \exp \left[-k_{\mathrm{cat}}(t-\tau)\right] \mathrm{d} \tau\right)\right] .
\end{aligned}
$$

Integral Eqs. (11) and (12) are seen as general mathematical solutions of the protein-film EEC' electrode mechanism under chronoamperometric conditions. The numerical solutions of Eqs. (11) and (12) in SWV conditions were obtained by using the method of Nicholson and Olmstead 
[35]. The time increment $d$ was defined as $d=1 /(50 f)$, where $f$ is the frequency of the potential SW steps. This means that each SW half-period $\tau / 2$ is divided into 25 increments. The square-wave signal is a train of cathodic and anodic pulses superimposed on a staircase potential ramp. The height of each cathodic and anodic pulse is equal and designated as the square-wave amplitude $E_{\mathrm{sw}}$. Additionally, the SW potential signal features a staircase potential step $\Delta E$. In Refs. $[34,36]$ we offered free files containing all details in respect to the definition of the potential signal in SWV, as well as facts about the calculation procedure in MATHCAD.

The features of the calculated voltammograms of the considered protein-film $\mathrm{EEC}^{\prime}$ mechanism depend mainly on three dimensionless parameters: $K_{1}, K_{2}$ and $\gamma . K_{1}$ and $K_{2}$ are designated as the electron transfer kinetic parameters for the first and the second redox steps, respectively. These dimensionless kinetic parameters are defined as $K_{1}=k_{\mathrm{s}, 1} / f$, and $K_{2}=k_{\mathrm{s}, 2} / f$, where $f$ is the SW signal frequency. The effect of the catalytic reaction is portrayed via the dimensionless catalytic parameter $\gamma$ that is defined as $\gamma=k_{\text {cat }} / f$. The dimensionless currents of the first and the second electron transfer steps are defined as $\Psi_{1}=I_{1} /\left[n F S f \Gamma^{*}\right]$ and $\Psi_{2}=I_{2} /\left[n F S f \Gamma^{*}\right]$, respectively. The overall dimensionless current for the reaction mechanism (I) is defined as $\Psi=\Psi_{1}+\Psi_{2}$.

In order to check the accuracy and correctness of the model, we compared the results of the surface $\mathrm{EEC}^{\prime}$ mechanism with those of a simple two-step surface redox reaction (i.e. surface EE reaction) [30] described by reaction scheme (II):

$\mathrm{A}_{(\mathrm{ads})}+\mathrm{ne}^{-} \rightleftarrows \mathrm{B}_{(\mathrm{ads})}+\mathrm{ne}^{-} \rightleftarrows \mathrm{C}_{(\mathrm{ads})}$.

If the value of the catalytic parameter $\gamma$ in the $\mathrm{EEC}^{\prime}$ mathematical model was set to be very small (i.e. $\gamma<0.00001$ ), then the theoretical voltammograms of the protein-film $\mathrm{EEC}^{\prime}$ reaction (I) and that of two step surface EE redox reaction (II) were identical, thus confirming the correctness of the developed theoretical protein-film EEC ${ }^{\prime}$ mechanism. The procedure for the numerical simulations of the reaction (II) is described elsewhere [30]. In addition to the kinetic parameters $\gamma, K_{1}$ and $K_{2}$, the features of the calculated SW voltammograms of the protein-film EEC' mechanisms depend also on the number of exchanged electrons in both steps $n_{1}$ and $n_{2}$, the electron transfer coefficients $\alpha_{1}$ and $\alpha_{2}$ (for the sake of simplicity, it is assumed in the model that $n=n_{1}=n_{2}=1$, and $\alpha=\alpha_{1}=\alpha_{2}=0.5$ ), the temperature $T$, and the potential modulation parameters (frequency- $f$, amplitude$E_{\mathrm{sw}}$, and potential step $\Delta E$ ). Similarly as by the simple surface $\mathrm{EC}^{\prime}$ mechanism $[14,16,17,20,22,23,25,32]$, the features of the calculated SW voltammograms obtained for this specific surface $\mathrm{EEC}^{\prime}$ system strongly depend on the magnitude of the chemical (or catalytic) rate constant. Besides the rate of the catalytic reaction and kinetics of both electron transfer steps, the features of the theoretical SWV voltammograms of the surface $\mathrm{EEC}^{\prime}$ mechanism are strongly affected by one "virtual" thermodynamic parameter $\left(E_{\mathrm{f}}\right)$ defined as a potential difference in the standard redox potentials between both electron transfer steps, i.e. $E_{\mathrm{f}}=E_{\mathrm{B} / \mathrm{C}}^{\ominus}-E_{\mathrm{A} / \mathrm{B}}^{\ominus}$. Because of the specificity of this redox mechanism, we show by most of the calculated voltammograms not only the net current, but also the forward and the backward current components. In the mathematical model, we defined the forward (reduction) current as positive, while the backward (reoxidation) current is negative. The net current is simply defined as a difference between the forward and the backward currents (it is always assigned by bold line at calculated voltammograms). All the potentials at the simulated voltammograms are referred $v s$. the standard redox potential $E_{\mathrm{A} / \mathrm{B}}^{\ominus}$ of the first electrochemical step. All theoretical calculations have been performed by using the MATHCAD software. A detailed description of the simulation procedure of some representative redox mechanisms in MATHCAD program is provided in our previous works [34,36], and one can use those files for free.

\section{Results and discussion}

Shown in Fig. 1 are three calculated SW voltammograms for quasireversible protein-film $\mathrm{EEC}^{\prime}$ reactions, by which the second electrochemical step is coupled with a catalytic regenerative reaction. The voltammograms have been calculated for three various potential differences $\left(E_{\mathrm{B} / \mathrm{C}}^{\ominus}-E_{\mathrm{A} / \mathrm{B}}^{\ominus}\right)$ between the first and the second electrochemical steps, while the catalytic parameter $\gamma$ was set to be very small $(\gamma \rightarrow 0)$. Obviously, the shape of the calculated voltammograms is strong function of the difference between the standard redox potentials of the two electron transfer reactions. In the first boundary condition a single voltammetric response is observed, if the standard redox potential of the second reduction step is more positive or the same as that of the first reduction step (Fig. 1A). The second limiting situation exists when the standard redox potential of the second electron transfer step $E_{\mathrm{B} / \mathrm{C}}^{\ominus}$ in reaction scheme (I) is at least $100 \mathrm{mV}$ more negative than that of the first reduction step $E_{\mathrm{A} / \mathrm{B}}^{\ominus}$. Under such circumstances, two well-separated voltammetric processes are observed (Fig. 1C). The intermediate situation is most complicated since it results in highly overlapped voltammograms, if the value of the standard redox potential of the second reduction step $E_{\mathrm{B} / \mathrm{C}}^{\ominus}$ is $20 \mathrm{mV}$ to $90 \mathrm{mV}$ more negative then the value of standard redox potential of the first reduction step $E_{\mathrm{A} / \mathrm{B}}^{\ominus}$, (Fig. 1B). Correspondingly, it is quite useful to elaborate the features of the considered protein-film $\mathrm{EEC}^{\prime}$ mechanisms via the two limiting situations in respect to the differences of the standard redox potentials of the two electron transfer steps:

Case A The energy of the second electron transfer step is smaller or equal to that of the first electron transfer step, or $E_{\mathrm{B} / \mathrm{C}}^{\ominus} \geq E_{\mathrm{A} / \mathrm{B}}^{\ominus}$; and

Case B The energy of the electron transfer for the second electrochemical step is more negative for at least $-100 \mathrm{mV}$ or more than that of the first electrochemical step, or $E_{\mathrm{B} / \mathrm{C}}^{\ominus}-E_{\mathrm{A} / \mathrm{B}}^{\ominus} \leq-$ $100 \mathrm{mV}$.

3.1. Case A. Features of calculated voltammograms of the protein-film $E E C^{\prime}$ mechanism for $E_{\mathrm{B} / \mathrm{C}}^{\ominus} \geq E_{\mathrm{A} / \mathrm{B}}^{\ominus}$

If the standard redox potential of the second reduction step $E_{\mathrm{B} / \mathrm{C}}^{\ominus}$ by the considered protein-film EEC mechanism is more positive (or equal) than that of the first reduction step $E_{\mathrm{A} / \mathrm{B}}^{\ominus}$, then (mainly) a single $\mathrm{SW}$ voltammogram is observed. This is because the second reduction step will occur at the very same potential required for the first reduction step. Such scenario exists by some proteins and other biomolecules containing quinone-moieties as redox active centers $[7,37]$. By these proteins, the redox conversion of quinone to hydroquinone usually goes via formation of a semiquinone radical as an intermediate. Under certain circumstances (in strong acidic $\mathrm{pH}$ regions), the conversion of semiquinone to hydroquinone commonly requires less (or identical) energy than the conversion of quinone to semiquinone [7], so both steps will be portrayed in a single voltammetric process. Although the consecutive electron-transfer steps in such scenario can be coupled by protonation steps, when the protonation step is very fast, it can be approximated that the mechanism of redox sequence quinone-semiquinone-hydroquinone complies with the two-step surface EE mechanism [37]. The features of the calculated SW voltammograms in such situation depend mainly on the value of the dimensionless catalytic parameter $\gamma$, but they are also affected by the values of the electron transfer kinetic parameters $K_{1}$ and $K_{2}$. Generally, if the dimensionless catalytic parameter is quite small $(\gamma \rightarrow 0)$, then the kinetic of the entire EEC' reaction is governed by the kinetic of the first electron transfer step. As a result, the voltammetric response of $\mathrm{EEC}^{\prime}$ protein-film mechanism converges to 

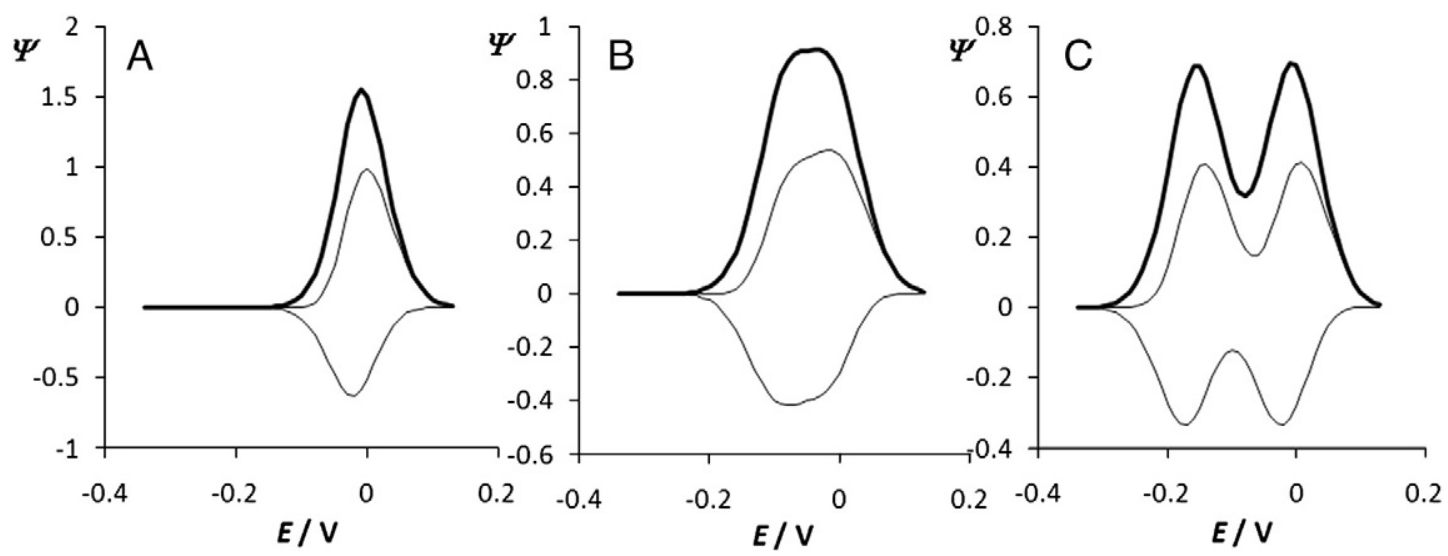

Fig. 1. Square-wave voltammograms of the protein-film $\mathrm{EEC}^{\prime}$ mechanism calculated for $E_{\mathrm{B} / \mathrm{C}}^{\ominus}=E_{\mathrm{A} / \mathrm{B}}^{\ominus}(\mathrm{A}) ; E_{\mathrm{B} / \mathrm{C}}^{\ominus}-E_{\mathrm{A} / \mathrm{B}}^{\ominus}=-70 \mathrm{mV}(\mathrm{B})$ and $E_{\mathrm{B} / \mathrm{C}}^{\ominus}-E_{\mathrm{A} / \mathrm{B}}^{\ominus}=-150 \mathrm{mV}(\mathrm{C})$. Number of electrons was $n_{1}=n_{2}=1$, electron transfer coefficient was $\alpha=\alpha_{1}=\alpha_{2}=0.5$, temperature $T=298 \mathrm{~K}$, amplitude $E_{\mathrm{sw}}=40 \mathrm{mV}$, and potential step of $\Delta E=10 \mathrm{mV}$. The values of the dimensionless kinetic parameters were $K_{1}=1$ and $K_{2}=1$, while the value of the dimensionless catalytic parameter was set to $\gamma=0.000001$.

that of a two-step surface EE reaction. The features of the protein-film EE reaction under conditions of SWV are described in more details elsewhere $[17,30,34,38]$.

At the beginning of the discussion in this chapter, it is important to give hints for distinguishing the successive two-step EE reaction $[30,38]$ from the simple two-electrons one-step surface redox reaction $[14,16,17,24]$. In our previous publication [30] we have shown that the features of the half-peak widths of net square-wave voltammograms can give relevant information to solve this problem. For both, the successive two-step EE reaction and for simple twoelectron one-step surface redox reaction, the half-peak widths decrease with decreasing of the SW frequency. However, the values of the half-peak widths of the SW voltammograms for the successive two-step EE reaction are on average $40 \mathrm{mV}$ broader than that of the one-step two-electron reaction $[29,30]$. This information can be of help to resolve (qualitatively) the doubts whether a given voltammogram is due to successive two-step EE reaction, or it is the result of a simple one-step reaction.

By given kinetics of both redox steps of a protein-film $\mathrm{EEC}^{\prime}$ reaction (for $E_{\mathrm{B} / \mathrm{C}}^{\ominus} \geq E_{\mathrm{A} / \mathrm{B}}^{\ominus}$ ), it is quite useful to study the effect of the catalytic parameter to the features of calculated SW voltammograms. Shown in Fig. 2 is the effect of the catalytic parameter $\gamma$ to the features of calculated voltammograms in situation of $E_{\mathrm{B} / \mathrm{C}}^{\ominus}=E_{\mathrm{A} / \mathrm{B}}^{\ominus}$, if both $K_{1}$ and $K_{2}$ fall within the quasireversible region of electron transfer. By increasing the value of catalytic parameter $\gamma$ one observes a linear increase of the net peak-currents of calculated SW voltammograms. A quite distinctive feature that is typical for all catalytic mechanisms studied under voltammetric conditions is the notable rising of both branches of the forward and backward currents at more negative potentials. This phenomenon is due to the unremitting effect of the catalytic reaction that supplies permanently electroactive material B during the whole measuring time in SWV [30,34]. Another remarkable feature by this mechanism is seen in the backward branch of the current, which gets the same sign as the forward current in the potential regions after the faradaic voltammetric response appears (see the features of the branches of both forward and backward currents at the left-side of the voltammograms in Fig. 2). If the catalytic parameter $\gamma$ gets values higher than $\sim 1.0$, then the backward (reoxidation) component of the SWV response gets the same shape and sign as the forward (reduction) component. Under such circumstances, the rate of the catalytic reaction is very large, hence causing immediate transformation of entire amount of the reduced species $\mathrm{C}$ back to the oxidized form B. Consequently, during the time scale of the voltammetric experiment the reoxidation process is significantly hindered (Fig. 2D). Nevertheless, though the shapes of the forward and backward components suffer big changes, this phenomenon exhibits no influence on the profile of the net-SW voltammogram. Whatever the value of the catalytic parameter is, the net-SWV response gets always a well-defined shape (see the netvoltammogram in Fig. 2D). The origin for this effect is found in the very specific manner of the current sampling in square-wave voltammetry [17]. From an analytical point of view, this feature is quite an important advantage of the SWV over the other voltammetric techniques, because the parameters of the net-SW voltammograms get easily measurable even at very pronounced catalytic effects. This is not the case by catalytic mechanism studied with other voltammetric techniques [32]. More detailed elaboration of the effects of catalytic parameter $\gamma$ to the features of calculated SW voltammograms can be found elsewhere $[17,25,32]$.

At this point we want to stress that the pace of rising of the net-peak currents by the $\mathrm{EEC}^{\prime}$ protein-film mechanism (for $E_{\mathrm{B} / \mathrm{C}}^{\ominus}=E_{\mathrm{A} / \mathrm{B}}^{\ominus}$ ) is somewhat higher than that by the simple one-step surface $\mathrm{EC}^{\prime}$ mechanism. The reason for this is due to the additional supply of $\mathrm{B}$ during the measuring time of the experiment (a sort of "pseudocatalytic" effect). Under such circumstances, the compound B is generated not only via the catalytic regeneration from $\mathrm{C}$, but also additionally via the electrochemical conversion of $\mathrm{A}$ that also occurs at $E_{\mathrm{B} / \mathrm{C}}^{\ominus}=E_{\mathrm{A} / \mathrm{B}}^{\ominus}$. This effect is likely responsible to higher pace of the catalytic currents measured by considered $\mathrm{EEC}^{\prime} v$ s. the one-step $\mathrm{EC}^{\prime}$ protein-film mechanism [25]. In order to get better understanding of the effect of the catalytic reaction to the calculated voltammetric curves, we remark that any variations from reversible behavior are related not to the absolute value of the pseudo-first order rate constant for the catalytic reaction $\left(k_{\text {cat }}\right)$, but to the value of $k_{\text {cat }}$ relative to the time scale of the experiment. For example, if the time-scale of the experiment is decreased (i.e. by increasing the SW frequency or the scan rate), there will be also less time available for the catalytic reaction to take place, so the effect of the catalytic reaction will be minimized.

An inherent feature of all protein-film reactions studied in SWV is the "splitting" of the net-voltammetric response [16,17,24,39]. The "splitting" phenomenon is typical for all surface redox systems exhibiting a fast and chemically reversible electron transfer step $[17,39]$. Commonly, the net SW voltammogram splits into two peaks as a result of the large separation between the cathodic and anodic components of the SW voltammograms [39]. The potential separation between the split SW peaks is sensitive to the redox kinetics, and it might be explored for estimating the standard rate constants of the electron transfer steps according to the procedure elaborated elsewhere $[17,30,39]$. By the considered case (for $E_{\mathrm{B} / \mathrm{C}}^{\ominus} \geq E_{\mathrm{A} / \mathrm{B}}^{\ominus}$ ) of the catalytic protein-film EEC' mechanism, the splitting of the calculated net $S W$ voltammograms occurs only if the kinetics of the first electron transfer step is fast. Under such circumstances, the calculated net SW voltammograms split into two peaks that are symmetrically located around the value of the standard redox potential $E_{\mathrm{A} / \mathrm{B}}^{\ominus}$ (Fig. 3A). 

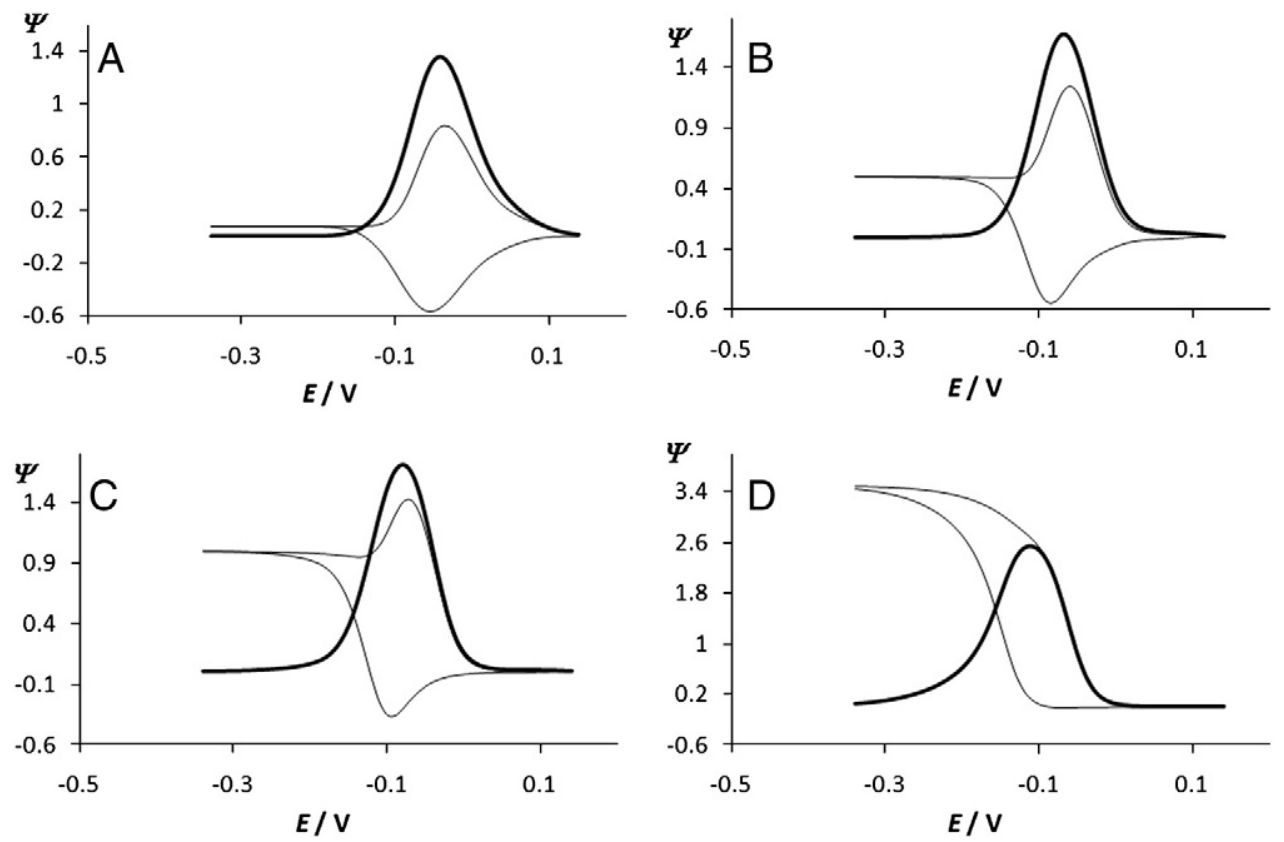

Fig. 2. Case $A$ : $E_{\mathrm{B} / \mathrm{C}}^{\ominus}=E_{\mathrm{A} / \mathrm{B}}^{\ominus}$. Effect of the catalytic parameter $\gamma$ to the features of calculated $S W$ voltammograms of protein-film $E E C^{\prime}$ mechanism. The values of the kinetic parameters were set to $K_{1}=K_{2}=0.6$, while the values of the dimensionless catalytic parameters were $\gamma=0.075(\mathrm{~A}), 0.5(\mathrm{~B}), 1$ (C) and 3 (D). The other simulation parameters were the same as those in Fig. 1 .

Shown in Fig. 3B-D is the effect of the dimensionless catalytic parameter $\gamma$ to the features of the calculated voltammograms, in situations of fast electron transfers of both electrochemical steps. Remarkably, a quite pronounced catalytic effect appears at smaller values of $\gamma$. This implies that the fast and reversible protein-film reactions are more sensitive to the catalytic regenerative reaction than the quasireversible redox systems (compare the $\gamma$ values at Figs. 3B and 2B, for example). An increase of the catalytic parameter $\gamma$ is followed by a linear increase of the voltammetric peak located at more negative potentials. When the catalytic parameter $\gamma$ reaches values higher than $\sim 0.8$, then the phenomenon of splitting peaks vanishes (see voltammogram D at Fig. 3). The net-voltammetric
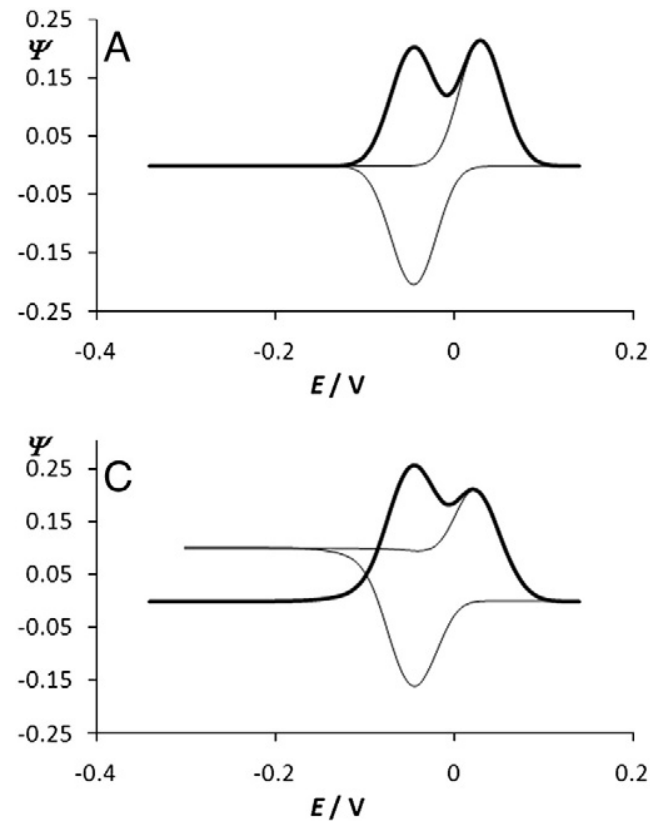

response now consists of a single peak that further gains in its intensity by increasing of $\gamma$. This behavior is quite similar to that described by a one-step surface catalytic mechanism [25], and it can be used as additional qualitative diagnostic criterion to recognizing this complex redox mechanism.

3.2. Case B. Features of calculated voltammograms of the protein-film $E E C^{\prime}$ mechanism for $E_{\mathrm{B} / \mathrm{C}}^{\ominus}-E_{\mathrm{A} / \mathrm{B}}^{\ominus} \leq-100 \mathrm{mV}$

If the standard redox potential of the second electrochemical step $E_{\mathrm{B} / \mathrm{C}}^{\ominus}$ is $\leq-100 \mathrm{mV}$ than that of the first electrochemical step $E_{\mathrm{A} / \mathrm{B}}^{\ominus}$, then the calculated voltammograms of studied $\mathrm{EEC}^{\prime}$ mechanism
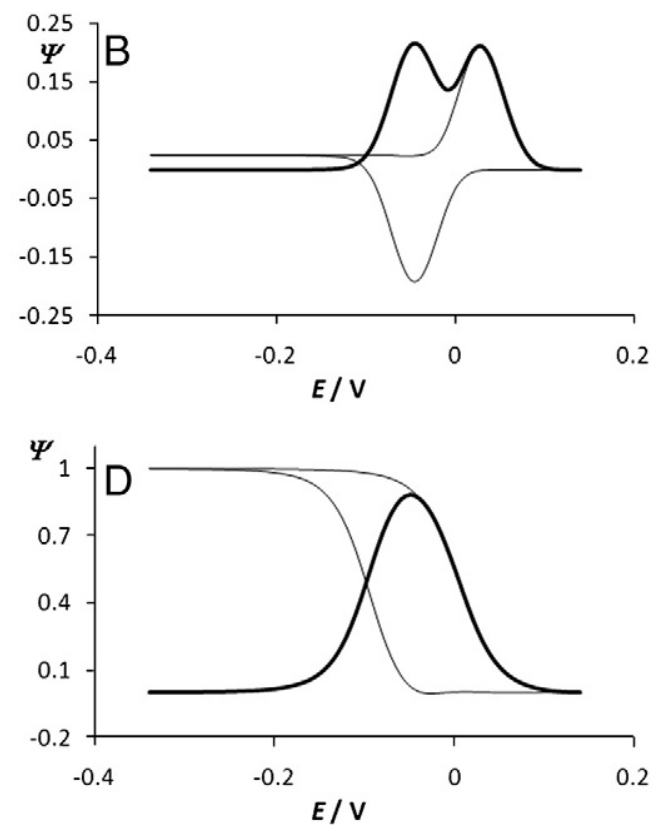

Fig. 3. Case $A: E_{\mathrm{B} / \mathrm{C}}^{\ominus}=E_{\mathrm{A} / \mathrm{B}}^{\ominus}$. Effect of the kinetics of the catalytic reaction to the features of the calculated SW voltammograms in case of fast kinetics of both electrochemical steps. The values of $K_{1}=K_{2}=5$, while the values of the dimensionless catalytic parameter were set to $\gamma=0.00001$ (A); 0.025 (B); 0.1 (C) and 1 (D). The value of the square-wave amplitude was $E_{\mathrm{sw}}=50 \mathrm{mV}$. Other simulation parameters were the same as those in Fig. 1 . 

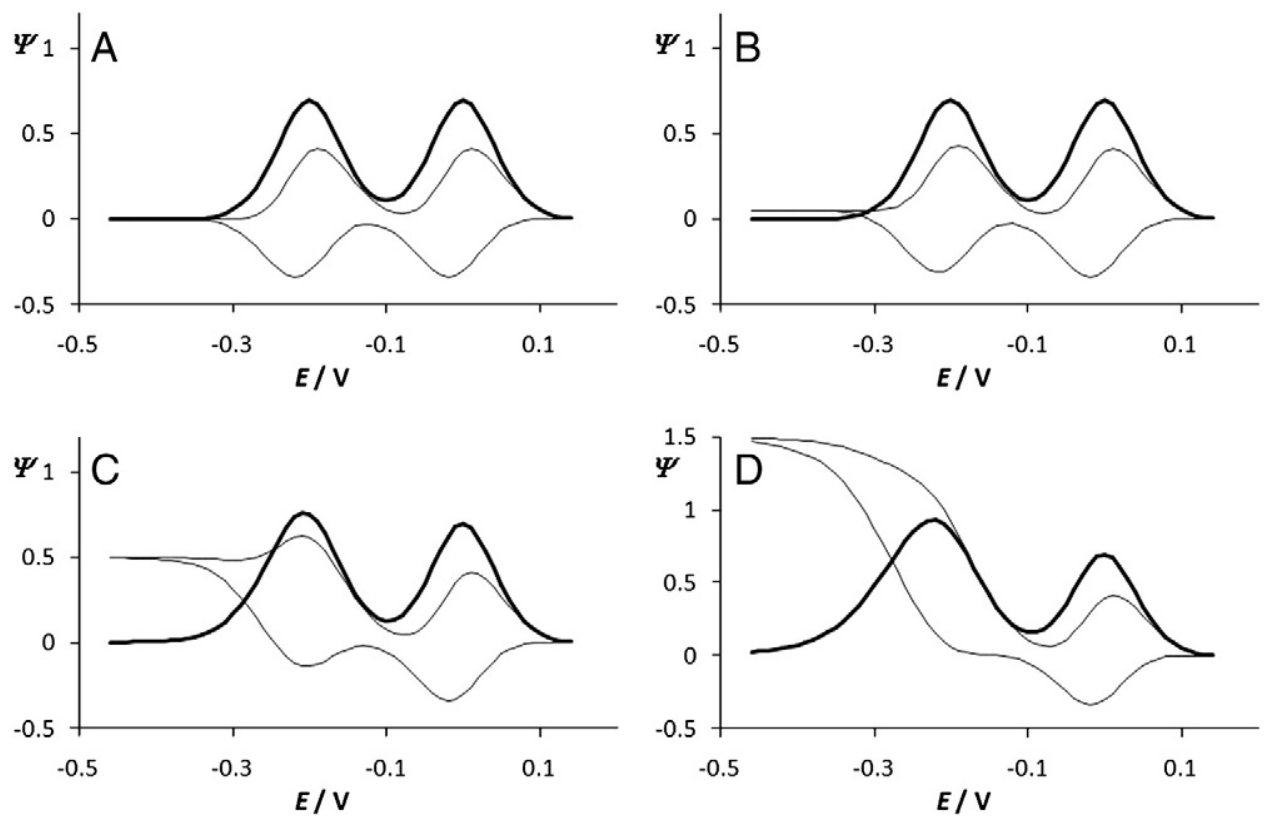

Fig. 4. Case $B: E_{\mathrm{B} / \mathrm{C}}^{\ominus}-E_{\mathrm{A} / \mathrm{B}}^{\ominus}=-200 \mathrm{mV}$. Effect of the catalytic parameter to the features of calculated SW voltammograms of protein-film EEC' mechanism. The values of the kinetic parameters were set to $K_{1}=K_{2}=1$, while the values of the dimensionless catalytic parameters were $\gamma=0.00001$ (A); 0.05 (B); 0.5 (C) and 1.5 (D). The other simulation parameters were the same as those in Fig. 1.

feature two, three or even four well-separated SW peaks, which depends mainly on the electron kinetics of both redox steps. In general, the features of the second electrochemical step of the protein-film EEC' mechanism are largely function of the kinetics of the first electrochemical step $[30,34]$. This is because the electrochemical transformation of compound $\mathrm{A}$ is the key pathway for the initial supply of compound B.

Shown in Figs. 4 and 5 are calculated SW voltammograms of protein-film $\mathrm{EEC}^{\prime}$ mechanism that portray the effect of the catalytic reaction, for $E_{\mathrm{B} / \mathrm{C}}^{\ominus}-E_{\mathrm{A} / \mathrm{B}}^{\ominus}=-200 \mathrm{mV}$. If the kinetics of both electrochemical steps falls within the quasireversible region, then two well-
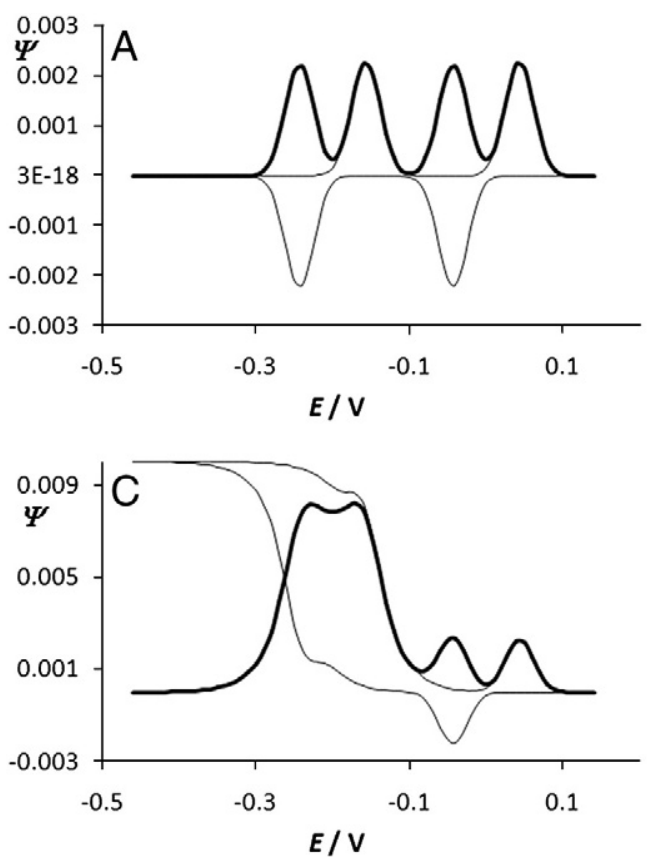

Fig. 5. Case $B$ : $E_{\mathrm{B} / \mathrm{C}}^{\ominus}-E_{\mathrm{A} / \mathrm{B}}^{\ominus}=-200 \mathrm{mV}$. Effect of the kinetics of the catalytic reaction to the features of calculated SW voltammograms in situation of very fast kinetics of both electrochemical steps. The value of $K_{1}=K_{2}=10$, while the values of the catalytic parameter were set to $\gamma=0.00001$ (A); 0.005 (B); 0.01 (C) and 0.1 (D). Square-wave amplitude $E_{\mathrm{sw}}$ was $50 \mathrm{mV}$, while other parameters were the same as those in Fig. 1.

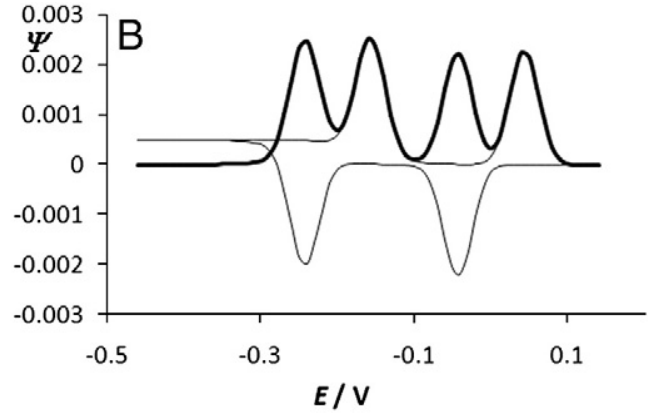

separated voltammetric peaks are observed (Fig. 4A). The dimensionless catalytic parameter $\gamma$ exhibits influence only to the voltammetric peak representing the second electrochemical process (Fig. 4B-D) in a way similar to that explained by the discussion of Figs. 2 and 3. Expectedly, the features of the first electrochemical step are not affected by the catalytic parameter $\gamma$. Under such circumstances, the behavior of the second electrochemical step of the protein-film EEC' mechanism is equivalent to that of a simple surface catalytic $\mathrm{EC}^{\prime}$ reaction described elsewhere [17,25,32]. This holds true only if the kinetics of the first electrochemical step by the EEC mechanism is big enough in order to supply initial electroactive

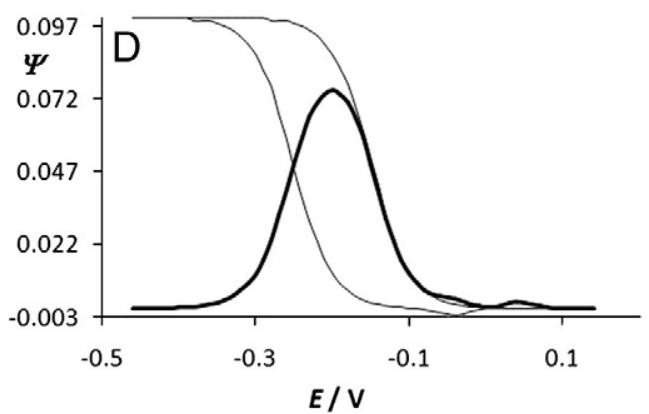


material of B. If the electron transfers of both electrochemical steps are very fast, then the calculated voltammograms feature four distinguished SW peaks, due to the splitting phenomenon by both redox steps (Fig. 5A) [17,30,39]. The effect of the catalytic parameter $\gamma$ to the features of split and well-separated SW peaks is shown in Fig. 5B-D. As previously noticed, the fast electrochemical reactions are much more susceptible to the effect of regenerative catalytic reaction. While the catalytic effect by the protein-film EEC' mechanism featuring slow second electron transfer step starts to be more pronounced by values of $\gamma \sim 0.05$, this effect by the same mechanism featuring fast second electron transfer step is obviously pronounced by much smaller values of $\gamma$, i.e. by $\gamma \sim 0.005$. Recall that higher values of the dimensionless catalytic parameter will produce disturbing of the splitting phenomenon, which will result in single and intensive net SW peak at more negative potentials (Fig. 5D). The intensity of this single peak almost completely covers the split peaks originating from the first electrochemical process positioned at more positive potentials.

If the difference between the standard redox potentials of the two electron transfer steps of the protein-film $\mathrm{EEC}^{\prime}$ reaction falls within the region $-20 \mathrm{mV}<E_{\mathrm{B} / \mathrm{C}}^{\ominus}-E_{\mathrm{A} / \mathrm{B}}^{\ominus}<-100 \mathrm{mV}$, then a rather complex intermediate situation is observed. Under these circumstances, the voltammetric peaks of both electron transfer steps will be highly overlapped, which will result in a complex voltammetric response that is rather difficult to be analyzed (see Fig. 6A). The response can be even further complicated if splitting or catalytic effect is associated to the second electrochemical step (Fig. 6B-C). If such experimental case is met, it is recommendable to use a very small potential step ( 0.1 to $1 \mathrm{mV}$ ), or some types of derivative voltammetric methods in order to obtain nicely resolved voltammetric peaks that will be suitable for analyzing.

\section{Conclusions}

Although the considered protein-film EEC' mechanism is one of the most complicated elaborated so far, it is always useful to provide some qualitative hints for recognizing this complex mechanism, and to recommend quantitative criteria that will enable estimation of relevant thermodynamic and kinetic parameters. A reliable indicator that helps in distinguishing between the catalytic mechanisms and other electrochemical systems coupled with chemical reactions is found in the features of intensive increase of both current branches by increasing the concentration of the substrate (or the catalytic reagent). This effect always exists in potential regions after the faradaic process occurs [14-17,21-25,32]. This phenomenon is typical for all catalytic mechanisms (EC', or $\left.E E C^{\prime}\right)$, while it does not exist by EC or CE systems [14,17,22-24,33,40-42]. When both electrochemical steps of the protein-film EEC' mechanism are separated for $100 \mathrm{mV}$ or more at the potential scale, then the kinetic and thermodynamic parameters of both redox steps, as well the rate constant of the catalytic reaction (i.e. the Michaelis-Menten constant) can be estimated by exploring the methodologies elaborated and described in more details in our previous papers $[17,30,39,41,42]$. For the determination of the standard rate constants of electron transfer one can use the features of "quasireversible maximum" or "split SW peaks" $[17,30,39]$. The phenomenon of quasireversible maximum can be used to estimate not only the electron transfer rate constant of the first redox step, but also that of the second redox step, even in the presence of catalytic effect. This is because the dimensionless catalytic parameter $\gamma$ does not influence the position of the "quasireversible maximum" (see Fig. 7) [25]. Alternatively, the electron transfer kinetic parameters can be estimated from the frequency dependence analysis of the half-peak widths of square-wave voltammograms, by using the analytical equations provided in our recent theoretical work [29]. For the determination of the electron transfer coefficients $\alpha$, one can also use the methodology elaborated in our recent work [28]. In order to calculate the Michaelis-Menten rate constant of catalytic reaction, one can take advantage of the methodology and analytical equations explained in our initial work concerning the surface $\mathrm{EC}^{\prime}$ mechanism $[17,25]$. Alternatively, one can use the equations corresponding to the regression lines corresponding to the linear dependence of the netpeak current of the second redox step $v$ s. the catalytic parameter $\gamma$ [see Fig. 8]. Note that the equations at Fig. 8 can be used only if the electron transfer coefficient $\alpha_{2}$ and the standard rate constant of electron transfer of the second redox step $k_{\mathrm{s}, 2}$ are previously estimated.

If both electrochemical steps in the protein-film $\mathrm{EEC}^{\prime}$ mechanism, however, occur at the same potential (i.e. if $E_{\mathrm{B} / \mathrm{C}}^{\ominus} \geq E_{\mathrm{A} / \mathrm{B}}^{\ominus}$ ), then the
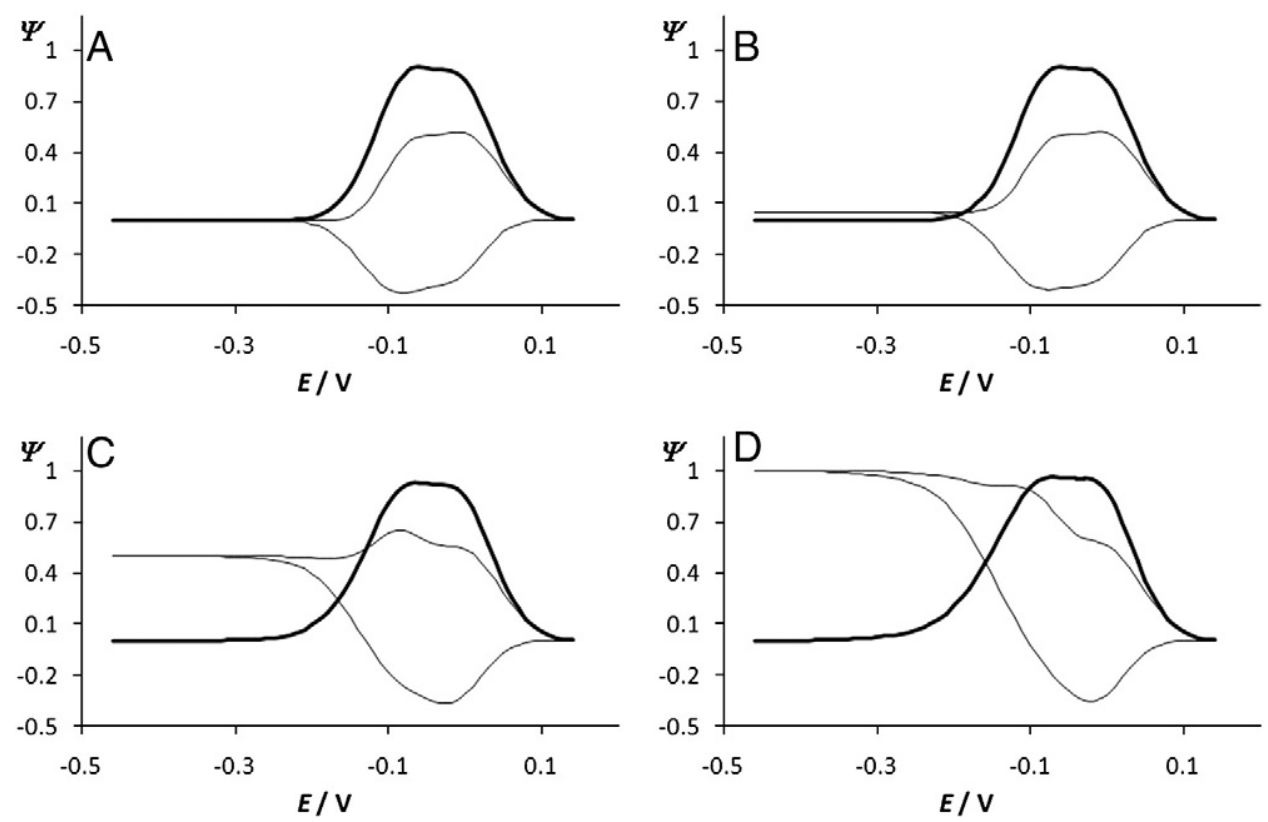

Fig. 6. Case of $E_{\mathrm{B} / \mathrm{C}}^{\ominus}-E_{\mathrm{A} / \mathrm{B}}^{\ominus}=-80 \mathrm{mV}$. Effect of the catalytic parameter to the features of SW voltammograms of protein-film EEC' mechanism simulated under circumstances where both voltammetric peaks are overlapping. The values of the dimensionless kinetic parameters were set to $K_{1}=K_{2}=1$, while the values of the catalytic parameters were $\gamma=0.00001$ (A); 0.05 (B); 0.5 (C) and 1 (D). The other simulation parameters were the same as those in Fig. 1. 


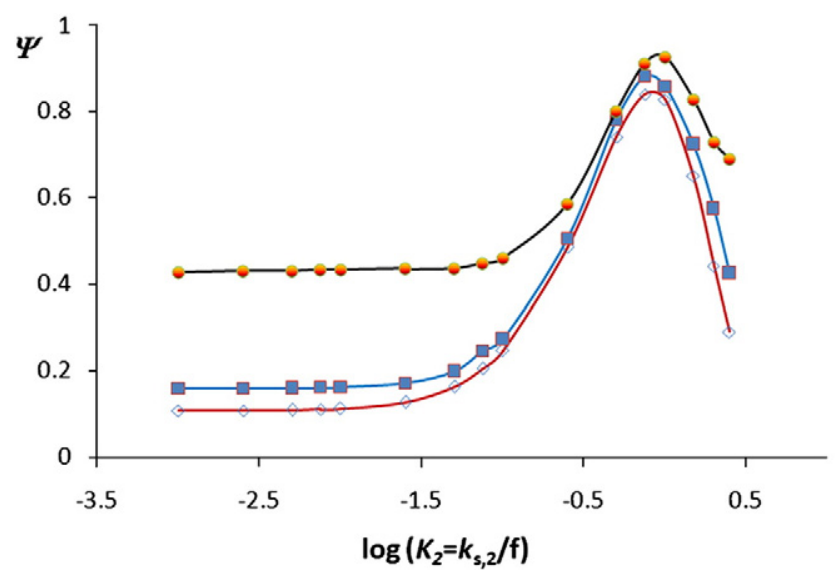

Fig. 7. Case $B$ : $E_{\mathrm{B} / \mathrm{C}}^{\ominus}-E_{\mathrm{A} / \mathrm{B}}^{\ominus}=-200 \mathrm{mV}$. Dimensionless catalytic parameter $\gamma$ does not affect the position of the quasireversible maximum. The "quasireversible maximums" are calculated for the second redox step of the $\mathrm{EEC}^{\prime}$ mechanism. The values of the dimensionless catalytic parameter were $\gamma=0.00001(\diamond) ; 0.05(\square)$ and $0.4(\bullet)$. Squarewave amplitude $E_{\mathrm{sw}}$ was $45 \mathrm{mV}$, while other parameters were the same as those in Fig. 1.

initial task is to recognize whether the net-voltammetric peak is due to the successive two-step EE reaction, or it is due to a single-step two-electron redox reaction. Practical example exists in recognizing whether a given voltammetric signal is due to a single-step twoelectron reduction of quinone to hydroquinone, or it is a result of successive two-steps one-electron reductions of quinone to semiquinone and of semiquinone to hydroquinone that sometimes occur at the same potential $[7,37]$. This can be recognized only from the examination of the value of the half-peak width of the square-wave voltammograms, which is quite different for the successive two-step surface EE reaction and a single-step two-electron reactions [see Ref. [30] for more details]. In the real experiment of an $\mathrm{EEC}^{\prime}$ system, an increase of the concentration of catalytic reagent will produce a quite complicated effect, if $E_{\mathrm{B} / \mathrm{C}}^{\ominus} \geq E_{\mathrm{A} / \mathrm{B}}^{\ominus}$. This is because the catalytic reagent will be able to catalyze not only the regeneration of $B$ from $C$, but also the regeneration of $A$ from $B$. The final output of this effect will be portrayed in supplementary increasing of the current components due to the multiplied catalytic effect. Unfortunately, such an effect will make almost impossible task to determine the Michaelis-Menten catalytic rate constant in situation of $E_{\mathrm{B} / \mathrm{C}}^{\ominus} \geq E_{\mathrm{A} / \mathrm{B}}^{\ominus}$.

All mentioned theoretical features of considered protein-film $E^{\prime} C^{\prime}$ mechanism in this work can be of big practical relevance for studying the redox features of many proteins containing quinone moiety or polyvalent ions of transitions metals as $\mathrm{Mo}, \mathrm{Mn}, \mathrm{W}$, or Co as redox

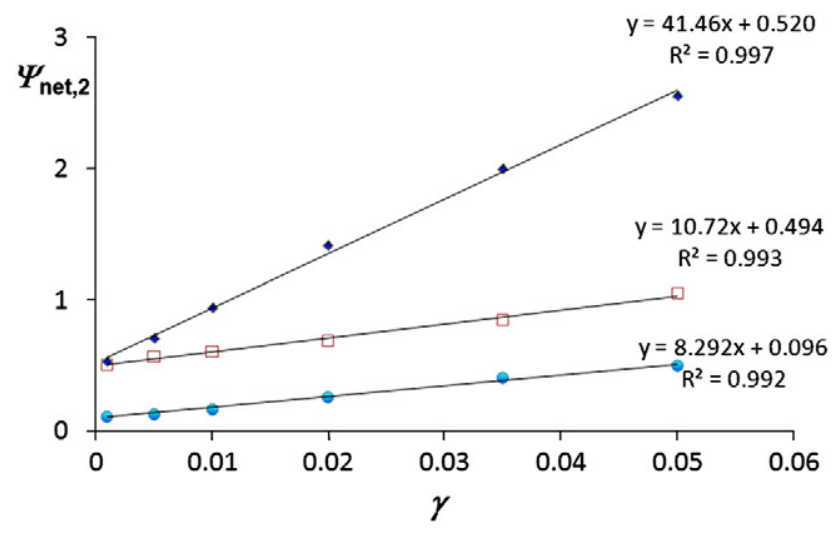

Fig. 8. Case $B$ : $E_{B / C}^{\ominus}-E_{A / B}^{\ominus}=-200 \mathrm{mV}$. Effect of the catalytic parameter $\gamma$ to the net-peak current $\Psi_{\text {net,2 }}$ of the second redox step. The values of the dimensionless parameter of the second redox step were $K_{2}=0.05(\bullet) ; 0.5(\square)$ and $2(\bullet)$. The value of $K_{1}$ was 0.5 , while the other parameters were the same as those in Fig. 1. centers [26]. A relevant biological example of the elaborated $\mathrm{EEC}^{\prime}$ mechanism is found by the processes of water oxidation to oxygen $\left(\mathrm{O}_{2}\right)$ by the Photosystem II (PSII or P680) [43,44]. It is well-known that the dioxygen molecules are derived from water that is oxidized to $\mathrm{O}_{2}$ by the PSII enzyme. In the PSII redox mechanism, a tetramanganese cluster (known also as oxygen-evolving complex-OEC) is oxidized to reduce $\mathrm{P}_{680}{ }^{+}$, readying the primary electron donor for another photochemical charge separation and creating oxidizing equivalents that oxidize water to $\mathrm{O}_{2}$. The main task of the OEC is to couple successive one-electron reductions of $\mathrm{P} 60^{+}$to four-electron oxidations of water to $\mathrm{O}_{2}$. During the water oxidation processes, the $\mathrm{OEC}$ is repeatedly oxidized (one electron at a time) by $\mathrm{P} 60^{+}$until, when the OEC is oxidized four times, it converts water to $\mathrm{O}_{2}$ and resets itself to its most reduced state [43]. The OEC is electrically linked to P680 by a redox-active tyrosine residue. The oxidized form of tyrosine reside is the radical species, which exists in the neutral deprotonated form $[43,44]$. A recent paper revealing the redox features of PSII in protein-film voltammetric mode [45] describes quite similar features of PSII-OEC system to those described in this theoretical work. The work [45] is seen as a most relevant example to the protein-film $\mathrm{EEC}^{\prime}$ mechanism. Additional biological systems complying with the elaborated $\mathrm{EEC}^{\prime}$ mechanism one finds by the redox transformation of Rhodobacter capsulatus Xanthine Dehydrogenase [46]. This Mo-containing enzyme undergoes two-step successive reduction of $\mathrm{Mo}^{\mathrm{VI} / \mathrm{V}}, \mathrm{Mo}^{\mathrm{V} / \mathrm{V}}$ by which the second redox step is catalyzed [46], thus behaving similarly to described scenario in Case B of the Results and discussion section in this manuscript.

\section{Acknowledgment}

Rubin Gulaboski thanks Alexander von Humboldt Stiftung for providing a Return postdoctoral fellowship. This work is also supported by Alexander von Humboldt Stiftung via the joint German-Macedonian project from the Research Group Linkage Programme 3.4-Fokoop-DEU/1128670.

\section{References}

[1] F.A. Armstrong, Bioelectrochemistry of Biomacromolecules, Birkhauser, Basel, 1997.

[2] F.A. Armstrong, H.A. Heering, J. Hirst, Reactions of complex metalloproteins studied by protein-film voltammetry, Chem. Soc. Rev. 26 (1997) 169-179.

[3] F.A. Armstrong, Voltammetry of proteins, in: A.J. Bard, M. Stratmann, G.S. Wilson (Eds.), Encyclopedia of Electrochemistry, Vol. 9, Wiley VCH, Weinheim, 2002.

[4] C. Leger, S.J. Elliott, K.R. Hoke, L.J.C. Jeuken, A.K. Jones, F.A. Armstrong, Enzyme electrokinetics: using protein film voltammetry to investigate redox enzymes and their mechanisms, Biochemical 42 (2003) 8653-8662.

[5] J.P. McEvoy, F.A. Armstrong, Protein film cryovoltammetry: demonstrations with a $7 \mathrm{Fe}([3 \mathrm{Fe}-4 \mathrm{~S}]+[4 \mathrm{Fe}-4 \mathrm{~S}])$ ferredoxin, Chem. Commun. (1999) 1635-1636.

[6] J. Hirst, F.A. Armstrong, Fast-scan cyclic voltammetry of protein films on pyrolytic graphite edge electrodes: characteristics of electron exchange, Anal. Chem. 70 (1998) 5062-5071.

[7] P.N. Bartlett, Bioelectrochemistry: Fundamentals, Experimental Techniques and Applications, Wiley, New York, 2008.

[8] A. Mertens, N. Shiraishi, W.H. Campbell, Recombinant expression of molybdenum reductase fragments of plant nitrate reductase at high levels in Pichia pastoris, Plant Physiol. 123 (2000) 743-756.

[9] L.J.C. Jeuken, J.P. McEvoy, F.A. Armstrong, Insights into gated electron-transfer kinetics at the electrode-protein interface: a square wave voltammetry study of the blue copper protein azurin, J. Phys. Chem. B 106 (2002) 2304-2313.

[10] F.A. Armstrong, Protein film voltammetry: revealing the mechanisms of biological oxidation and reduction, Russ. J. Electrochem. 38 (2002) 49-62.

[11] Y.H. Wu, S.S. Hu, Biosensors based on direct electron transfer in redox proteins, Microchim. Acta 159 (2007) 1-17.

[12] J. Hirst, Elucidating the mechanisms of coupled electron transfer and catalytic reactions by protein film voltammetry, Biochem. Biophys. Acta 1757 (2006) 225-239.

[13] A.J. Bard, L.R. Faulkner, Electrochemical Methods, Fundamentals and Applications, John Wiley \& Sons, New York, 2001.

[14] J.J. Odea, J. Osteryoung, R.A. Osteryoung, Theory of square-wave voltammetry for kinetic systems, Anal. Chem. 53 (1981) 695-701.

[15] R.J. Dwayne Miller, G. McLendon, A.J. Nozik, A. Schmickler, F. Willig, Surface Electron Transfer Processes, Wiley, New York, 1995.

[16] J.J. Odea, J.G. Osteryoung, Characterization of quasi-reversible surface processes by square-wave voltammetry, Anal. Chem. 65 (1993) 3090-3097. 
[17] V. Mirceski, S. Komorsky-Lovric, M. Lovric, in: F. Scholz (Ed.), Square-wave Voltammetry-Theory and Application, Springer, Berlin, 2007.

[18] M. Lovric, Modeling of catalytic reaction in protein-film linear scan voltammetry at rotating disk electrode, Portugal, Electrochim. Acta 27 (2009) 505-515.

[19] T.M. Saccucci, J.F. Rusling, Modeling square-wave voltammetry of thin protein films using Marcus theory, J. Phys. Chem. B 105 (2001) 6142-6147.

[20] S.W. Feldberg, J.F. Campbell, The quasicatalytic mechanism: a variation of the catalytic (EC') mechanism, Anal. Chem. (2009) 8797-8800.

[21] F. Scholz, U. Schröder, R. Gulaboski, Electrochemistry of Immobilized Particles and Droplets, Springer, Berlin, 2005.

[22] R. Gulaboski, in: A.J. Bard, G. Inzelt, F. Scholz (Eds.), Electrochemical Dictionary, Springer, 2008.

[23] B.A. Brookes, R.G. Compton, Simulation of square wave voltammetry: quasireversible electrode processes, J. Phys. Chem. B 103 (1999) 9020-9028.

[24] J.G. Osteryoung, R.A. Osteryoung, Square-wave voltammetry, Anal. Chem. 57 (1985) A101-A110.

[25] V. Mirceski, R. Gulaboski, Surface catalytic mechanism in square-wave voltammetry, Electroanalytical 13 (2001) 1326-1334.

[26] A. Messerschmidt, R. Huber, K. Wieghardt, T. Poulos, Handbook of Metalloproteins, Wiley, 2001.

[27] V.Mirčeski, M. Lovrić, R. Gulaboski, Theoretical and experimental study of the surface redox reaction involving interactions between the adsorbed particles under conditions of square-wave voltammetry, J. Electroanal. Chem. 515 (2001) 91-99.

[28] R. Gulaboski, M. Lovric, V. Mirceski, I. Bogeski, M. Hoth, Protein-film voltammetry: a theoretical study of the temperature effect using square-wave voltammetry, Biophys. Chem. 137 (2008) 49-55.

[29] R. Gulaboski, M. Lovric, V. Mirceski, I. Bogeski, M. Hoth, A new rapid and simple method to determine the kinetics of electrode reactions of biologically relevant compounds from the half-peak width of the square-wave voltammograms, Biophys. Chem. 138 (2008) 130-137.

[30] V. Mirčeski, R. Gulaboski, A theoretical and experimental study of two-step auasireversible surface reaction by square-wave voltammetry, Croat. Chem. Acta 76 (2003) 37-48.

[31] V. Mirčeski, R. Gulaboski, Adsorptive stripping voltammetric behavior of probucole. Experimental and theoretical treatment, Microchim. Acta 138 (2002) 33.

[32] V. Mirčeski, R. Gulaboski, The surface catalytic mechanism: a comparative study with square-wave and staircase cyclic voltammetry, J. Solid State Electrochem. 7 (2003) 157-165.

[33] R. Gulaboski, V. Mirceski, M. Lovric, I. Bogeski, Theoretical study of a surface electrode reaction preceded by a homogeneous chemical reactions under conditions of square-wave voltammetry, Electrochem. Commun. 7 (2005) 515-522.

[34] R. Gulaboski, Surface ECE mechanism in protein film voltammetry-a theoretical study under conditions of square-wave voltammetry, J. Solid State Electrochem. 13 (2009) 1015-1024.

[35] R.S. Nicholson, M.L. Olmstead, in: J.S. Mattson, H.B. Mark, H.C. MacDonald (Eds.), Electrochemistry: Calculations, Simulation and Instrumentation, Marcel Dekker, New York, 1972, pp. 120-137.

[36] V. Mirceski, R. Gulaboski, I. Kuzmanovski, MATHCAD-a tool for numerical calculations of square-wave voltammograms, Bull. Chem. Technol. Macedonia 18 (1999) 57-64.

[37] a) C. Anthony, L.J. Zatman, The microbial oxidation of methanol. The prosthetic group of the alcohol dehydrogenase of Pseudomonas sp. M27: a new oxidoreductase prosthetic group, Biochem. J. 104 (1967) 960-969;

b) B.L. Crane, Biochemical functions of coenzyme Q10, J. Am. Coll. Nutr. 20 (2001) 591-598;

c) F.L. Crane, I.L. Sun, E.E. Sun, The essential functions of coenzyme Q, Cli. Investig. 71 (1993) S55-S59.

[38] J.J. O'Dea, J.G. Osteryoung, Square wave voltammetry for two step surface reductions, Anal. Chem. 69 (1997) 650-658.

[39] V. Mirceski, M. Lovric, Split square-wave voltammograms of surface redox reactions, Electroanal. 9 (1997) 1283-1287.

[40] F. Garay, M. Lovric, Square-wave voltammetry of quasi-reversible electrode processes with coupled homogeneous chemical reactions, J. Electroanal. Chem. 518 (2002) 91-102.

[41] S. Komorsky-Lovric, M. Lovric, Kinetic measurements of a surface-confined redox reaction, Anal. Chim. Acta 305 (1995) 248-255.

[42] S. Komorsky-Lovric, M. Lovric, Square-wave voltammetry of quasi-reversible surface redox reactions, J. Electroanal. Chem. 384 (1995) 115-122.

[43] B.A. Diner, R.D. Britt, R. on Photosystem II: the light-driven water: plastoquinone oxidoreductase, in: T.J. Wydrzynski, K. Satoh (Eds.), Advances in Photosynthesis and Respiration, 22, Springer, Dordrecht, The Netherlands, 2005, p. 207.

[44] J.P. McEvoy, G.W. Brudvig, Water-splitting chemistry of Photosystem II, Chem. Rev. 106 (2006) 4455-4483.

[45] K. Alcantara, B. Munge, Z. Pendon, H.A. Frank, J.F. Rusling, Thin film voltammetry of spinach Photosystem II. Proton-gated electron transfer involving the $\mathrm{Mn}_{4}$ cluster, J. Am. Chem. Soc. 128 (2006) 14930-14937.

[46] K.F. Aguey-Zinsou, P.V. Bernhardt, S. Leimkuehler, Protein film voltammetry of Rhodobacter capsulatus Xanthine Dehydrogenase, J. Am. Chem. Soc. 125 (2003) 15352-15358. 